\title{
Effect of Pretreatment and Annealing on Aluminum Coating Prepared by Physical Vapor Deposition on AZ91D Magnesium Alloys
}

\author{
Fan Liu ${ }^{3}$, Xu Chen ${ }^{3}$, Yuekun $\mathrm{Gu}^{1}$, Chao Ma ${ }^{1}$, Xiaopeng $\mathrm{Han}^{2}$, Yida Deng ${ }^{2}$, Wenbin $\mathrm{Hu}^{1,2,3}$, Cheng \\ Zhong $^{1,2, *}$ \\ ${ }^{1}$ Key Laboratory of Advanced Ceramics and Machining Technology (Ministry of Education), School \\ of Materials Science and Engineering, Tianjin University, Tianjin 300072, China \\ ${ }^{2}$ Tianjin Key Laboratory of Composite and Functional Materials, School of Materials Science and \\ Engineering, Tianjin University, Tianjin 300072, China \\ ${ }^{3}$ State Key Laboratory of Metal Matrix Composites, Department of Materials Science and \\ Engineering, Shanghai Jiao Tong University, Shanghai, 200240, China (The first and second authors \\ contributed equally) \\ *E-mail: cheng.zhong@tju.edu.cn
}

doi: $10.20964 / 2016.07 .57$

Received: 10 April 2016 / Accepted: 18 May 2016 / Published: 4 June 2016

\begin{abstract}
Magnesium alloys have been widely used in many fields owing to its light weight. However, their poor corrosion resistance has prevented their further applications. In this study, vacuum evaporation deposition coupled with the pretreatment of the AZ91D magnesium alloy substrates were employed to successfully prepare an aluminum coating on AZ91D magnesium alloy in an attempt to enhance its corrosion resistance. The surface morphology, corrosion resistance and adhesive strength of the coatings prepared from different pretreatments were systemically investigated. The effect of deposition time and annealing treatment on the surface morphology, corrosion resistance and adhesive strength was also examined. The results showed that the best corrosion resistance and highest adhesive strength of the aluminum coating were obtained for the specimen pretreated by $\mathrm{H}_{3} \mathrm{PO}_{4}$ etching. As the deposition time increases, a continuous and dense aluminum coating gradually forms on the surface of magnesium alloy following the typical island growth (Volmer-Weber) mode. The increase of deposition time enhances the corrosion resistance of magnesium alloy but has no effect on the adhesive strength between the coating and the substrate. With the increase of the annealing temperature, the coating of the sample becomes more uniform with better crystallinity of aluminum compared with unannealed sample.
\end{abstract}


Keywords: Magnesium alloy; Vacuum evaporation deposition; Pretreatment; Annealing; Corrosion resistance

\section{FULL TEXT}

(C) 2016 The Authors. Published by ESG (www.electrochemsci.org). This article is an open access article distributed under the terms and conditions of the Creative Commons Attribution license (http://creativecommons.org/licenses/by/4.0/). 